AperTO - Archivio Istituzionale Open Access dell'Università di Torino

Relationship between time interval from primary surgery to the start of taxane- plus platinumbased chemotherapy and clinical outcome of patients with advanced epithelial ovarian cancer: results of a multicenter retrospective Italian study

This is the author's manuscript

Original Citation:

Availability:

This version is available http://hdl.handle.net/2318/36367

since

Terms of use:

Open Access

Anyone can freely access the full text of works made available as "Open Access". Works made available under a Creative Commons license can be used according to the terms and conditions of said license. Use of all other works requires consent of the right holder (author or publisher) if not exempted from copyright protection by the applicable law. 
From the Department of Gynecology and Obstetrics, Department of Experimental Pathology, University of Pisa; Institute of Clinical Physiology, National Research Council, Pisa; Department of Gynecology and Obstetrics, University of Brescia, Brescia; Department of Gynecology and Obstetrics, University of Turin, Turin; and Department of Gynecology and Obstetrics, University of Padua, Padua; European Institute of Oncology, Milan, Italy Submitted March 8, 2004; accepted September 7, 2004

Authors' disclosures of potential conflicts of interest are found at the end of this article.

Address reprint requests to Angiolo Gadducci, MD, Department of Procreative Medicine, Division of Gynecology and Obstetrics, University of Pisa, Via Roma 56, Pisa, 56127, Italy; e-mail: a.gadducci@obgyn.med.unipi.it.

(C) 2005 by American Society of Clinical Oncology

0732-183X/05/2304-751/\$20.00

DOI: $10.1200 / J C O .2005 .03 .065$

\section{Relationship Between Time Interval From Primary Surgery to the Start of Taxane- Plus Platinum-Based Chemotherapy and Clinical Outcome of Patients With Advanced Epithelial Ovarian Cancer: Results of a Multicenter Retrospective Italian Study}

Angiolo Gadducci, Enrico Sartori, Fabio Landoni, Paolo Zola, Tiziano Maggino, Angelo Maggioni, Stefania Cosio, Eleonora Frassi, Maria Teresa LaPresa, Luca Fuso, and Renza Cristofani

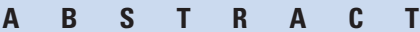

\section{Purpose}

To assess whether the interval from primary surgery to the start of taxane- plus platinum-based chemotherapy has any impact on the clinical outcome of advanced ovarian cancer patients.

\section{Patients and Methods}

The study was conducted on 313 patients who underwent surgery followed by taxane- plus platinum-based chemotherapy. The median follow-up of survivors was 30.7 months (range, 6 to 109 months).

\section{Results}

The $25 \%, 50 \%$, and $75 \%$ quantiles of intervals from surgery to the start of chemotherapy were 11, 21, and 31 days, respectively. After the sixth cycle, 102 patients achieved a pathologic complete response at second-look surgery and 98 obtained a clinical complete response but were not submitted to second-look surgery. Taking into consideration the best assessed response, a complete (either clinical or pathologic) response was found in 200 patients. Residual disease $(\leq 1 \mathrm{v}>1 \mathrm{~cm} ; P<.0001$ ) and ascites (absent $v$ present; $P=.003$ ) were independent predictive factors for achieving a complete response, whereas residual disease $(P=.001)$ and stage (IIc to III $v \mathrm{IV} ; P=.04$ ) were independent prognostic variables for survival. Conversely, statistical analyses failed to detect significant differences in complete response rates and survival among patients with an interval from surgery to chemotherapy shorter than 11 days, 12 to 21 days, 22 to 31 days, and longer than 31 days.

\section{Conclusion}

The interval from surgery to the start of taxane- plus platinum-based chemotherapy seems to have neither a predictive value for response to treatment nor a prognostic relevance for survival of advanced ovarian cancer patients.

\section{J Clin Oncol 23:751-758. (C) 2005 by American Society of Clinical Oncology}

\section{INTRODUCTION}

Advanced epithelial ovarian cancer is the most lethal gynecologic cancer. According to the International Federation of Gynecology and Obstetrics (FIGO) Annual Report No. 24 , the 5 -year survival was $58.5 \%$ for stage IIIa, $39.9 \%$ for stage IIIb, $28.7 \%$ for stage IIIc, and $16.8 \%$ for stage IV disease. ${ }^{1}$ Residual disease after initial surgery, ${ }^{2-6}$ tumor grade, ${ }^{3-5}$ and histologic types ${ }^{2,3,5,7}$ are the most commonly assessed clinicopathologic variables influencing the response rate to chemotherapy and survival rate. Recently, many efforts have been made to identify biologic parameters, such as DNA 
ploidy, ${ }^{3,8,9}$ oncogenes and tumor suppressor genes, ${ }^{8-15}$ growth factors and growth factor receptors, ${ }^{9,16,17}$ and degree of tumor angiogenesis, ${ }^{18-21}$ that have a predictive or prognostic value for advanced epithelial ovarian cancer.

Some experimental investigations on different animal models showed that the removal of the primary tumor accelerated metastatic tumor growth assessed as both gross tumor size and metastatic cell kinetics. ${ }^{22-26}$ The increase in tumor growth is probably due to a conversion of noncycling cells in $\mathrm{G}_{0}$ phase into proliferation. ${ }^{26}$ However, limited and conflicting data are currently available about the relationship between the time interval from surgery to the start of chemotherapy and treatment effectiveness in animal tumor models, ${ }^{27-29}$ and in human malignancies including epithelial ovarian cancer. ${ }^{30-35}$

The aim of this retrospective investigation was to assess whether the length of the interval from primary surgery to taxane- plus platinum-based chemotherapy has any impact on response to treatment and survival of patients with advanced epithelial ovarian cancer.

\section{PATIENTS AND METHODS}

This retrospective study was conducted on 313 patients who underwent primary surgery followed by taxane- plus platinum-based chemotherapy for advanced epithelial ovarian cancer at the Departments of Gynecology and Obstetrics of University of Brescia, Pisa, and Turin, and at the Department of Gynecologic Oncology of the European Institute of Oncology of Milan (Italy) between January 1994 and January 2003.

The tumor stage and histologic diagnosis of each patient were determined according to FIGO criteria and the histologic typing system of the WHO, respectively. Tumors were graded as well $\left(G_{1}\right)$, moderately $\left(G_{2}\right)$, or poorly $\left(G_{3}\right)$ differentiated.

The planned combination chemotherapy consisted of six cycles of paclitaxel plus carboplatin in 258 patients, epirubicin plus paclitaxel plus carboplatin in 18 patients, docetaxel plus carboplatin in 15 patients, ifosfamide plus paclitaxel plus cisplatin in 10 patients, paclitaxel plus cisplatin in seven patients, and epirubicin plus paclitaxel plus cisplatin in five patients.

The evaluation of the clinical course of disease was based on clinical examination, serum CA-125 assay, chest x-ray, abdominal-pelvic ultrasound, and computed tomography scan. Additional investigations were performed when appropriate. After the sixth cycle of chemotherapy, patients with no evidence of disease at clinical, serologic, sonographic, and radiologic examinations were defined as being in clinical complete response. Three to 5 weeks after the end of chemotherapy, a second-look surgery was usually proposed to clinically complete responders, mostly to patients enrolled onto clinical trials. A pathologic complete response at second-look surgery was defined as the disappearance of all macroscopic tumor deposits with negative peritoneal washing and negative multiple random biopsies. All patients with clinically or surgically detectable persistent disease, as well as some pathologically complete responders, received additional chemotherapy.

All patients were observed until they died or until July 2003. The median follow-up of survivors was 30.7 months (range, 6 to 109 months).
The SAS statistical package (release 8.2; SAS Institute, Cary, NC) was used for computations.

Time intervals from primary surgery to the start of chemotherapy were related to tumor stage, residual disease, and presence or absence of ascites using the median test.

Rates of complete response were compared to explicative variables using Pearson's $\chi^{2}$ test (or two-tailed Fisher's exact test when appropriate). Multiple logistic regression was carried out to investigate the relationship among the probability of achieving a complete response and the explanatory variables.

The cumulative probability of overall survival from the time of initial surgery was estimated by the product-limit method. The log-rank test was used to compare the homogeneity of survival functions across strata defined by categories of prognostic variables. The relationship between time interval from primary surgery to the start of chemotherapy and overall survival was also estimated using the nonparametric Spearman rank correlation coefficient (computed on unrecorded values). A multiple regression analysis based on the Cox proportional hazards model was used to test jointly the relative importance of variables as predictors of survival times.

\section{RESULTS}

The median age of patients was 56 years (range, 23 to 77 years). According to the FIGO classification, tumor stage was IIc in 24 patients, III in 249 patients, and IV in 40 patients. Histologically, 205 carcinomas were serous, 35 were endometrioid, 29 were undifferentiated, 26 were mixed, 13 were clear-cell, four were mucinous, and one was a malignant Brenner tumor. Tumor grade was $G_{1}$ in eight patients, $G_{2}$ in 82 patients, and $G_{3}$ in 223 patients. After initial surgery, 138 patients had residual disease $\leq 1 \mathrm{~cm}$ and 175 patients had a larger residual tumor. Ascites was detected in 217 patients. Time intervals from primary surgery to the start of chemotherapy ranged from 3 to 62 days. The $25 \%, 50 \%$, and $75 \%$ quantiles of intervals from primary surgery to the start of chemotherapy were 11,21 , and 31 days, respectively.

Time intervals from primary surgery to the start of chemotherapy were not related to residual disease $(\leq 1 v$ $>1 \mathrm{~cm}$; median, $20 v 22$ days; range, 5 to $62 v 3$ to 60 days; $P=$ not significant $[\mathrm{ns}]$ ) or absence or presence of ascites (median, $22.5 \vee 20$ days; range, 6 to $60 \vee 3$ to 62 days; $P=\mathrm{ns})$. Conversely, time interval was shorter for patients with stage IV disease compared with those with stage IIc to IV disease (median, $14 v 21$ days; range, 6 to $47 v 3$ to 62 days; $P=.0419)$.

Sixteen patients experienced disease progression early during first-line chemotherapy. After the sixth cycle of chemotherapy, 102 patients achieved a pathologic complete response at second-look surgery, 98 patients obtained a clinical complete response but were not submitted to second-look surgery, and 113 patients had clinically or surgically detectable persistent disease. Therefore, taking 
into consideration the best assessed response, a complete (either clinical or pathologic) response was observed in 200 patients.

Residual disease $(\leq 1 v>1 \mathrm{~cm})$ and ascites (absent $v$ present) were the only variables related to the chance of achieving a complete response to chemotherapy at both univariate $(P<.0001$ and $P=.0002$, respectively; Table 1$)$ and multivariate analysis $(P<.0001$ and $P=.003$, respectively; Table 2), whereas the interval from primary surgery to chemotherapy had no predictive value.

By log-rank test, overall survival was related to residual disease ( $\leq 1 \mathrm{~cm} v>1 \mathrm{~cm} ; P=.0003$; Fig 1 ), ascites (absent $v$ present; $P=.0161$; Fig 2 ), and tumor stage (IIc to III $v$ IV; $P=.0055$; Fig 3 ), but not to interval from primary surgery to chemotherapy (Fig 4 ), age (data not shown), histologic type (data not shown), and histologic grade (data not shown).

The nonparametric correlation between time interval from primary surgery to the start of chemotherapy and overall survival did not show any statistical significance (Spearman rank correlation coefficient $r_{\mathrm{S}}=0.02$; $P=$ ns; Fig 5).

The Cox proportional hazards model showed that residual disease $(P=.001)$ and tumor stage $(P=.04)$ were the only independent prognostic variables for overall survival (Table 3 ).

\section{DISCUSSION}

Cytoreductive surgery followed by paclitaxel- plus platinumbased chemotherapy represents the standard treatment for patients with advanced epithelial ovarian cancer. Current regimens are able to obtain a clinical complete response rate of approximately $50 \%$, a pathologic complete response rate of $25 \%$ to $30 \%$, a median progression-free survival of 15.5 to 22 months, and a median overall survival of 31 to 44 months. ${ }^{36-44}$ Randomized studies comparing paclitaxel plus cisplatin versus paclitaxel plus carboplatin showed that the two regimens are equally effective; the carboplatin combination is well tolerated. ${ }^{37,41,42,44} \mathrm{~A}$ recent randomized study revealed no difference in response rates, progression-free survivals, and early survival data between docetaxel plus carboplatin versus paclitaxel plus carboplatin, whereas a significant difference in toxicity profiles emerged between the two regimens, with less neurotoxicity and more myelosuppression for docetaxel plus carboplatin. ${ }^{45,46}$ Several ongoing phase III

\begin{tabular}{|c|c|c|c|c|}
\hline Variable & $\begin{array}{c}\text { Complete } \\
\text { Responders* }\end{array}$ & $\begin{array}{l}\text { No. of } \\
\text { Patients }\end{array}$ & $\%$ & $P$ \\
\hline \multicolumn{5}{|l|}{ Age, years } \\
\hline$\leq 56$ & 100 & 158 & 63.2 & \multirow[t]{2}{*}{ NS } \\
\hline$>56$ & 100 & 155 & 64.5 & \\
\hline \multicolumn{5}{|l|}{ Stage } \\
\hline II-III & 179 & 273 & 65.6 & \multirow[t]{2}{*}{ NS } \\
\hline IV & 21 & 40 & 52.5 & \\
\hline \multicolumn{5}{|l|}{ Grade } \\
\hline $\mathrm{G}_{1}-\mathrm{G}_{2}$ & 59 & 90 & 65.6 & \multirow[t]{2}{*}{ NS } \\
\hline $\mathrm{G}_{3}$ & 141 & 223 & 63.2 & \\
\hline \multicolumn{5}{|l|}{ Histologic type } \\
\hline Serous & 133 & 205 & 64.8 & \multirow[t]{2}{*}{ NS } \\
\hline Nonserous & 67 & 108 & 62.0 & \\
\hline \multicolumn{5}{|l|}{ Residual disease } \\
\hline$\leq 1 \mathrm{~cm}$ & 109 & 138 & 78.9 & \multirow[t]{2}{*}{$<.0001$} \\
\hline$>1 \mathrm{~cm}$ & 91 & 175 & 52.0 & \\
\hline \multicolumn{5}{|l|}{ Ascites } \\
\hline No & 76 & 96 & 79.1 & \multirow[t]{2}{*}{.0002} \\
\hline Yes & 124 & 217 & 57.1 & \\
\hline \multicolumn{5}{|c|}{$\begin{array}{l}\text { Interval time from primary surgery to the start of } \\
\text { chemotherapy, days }\end{array}$} \\
\hline$\leq 11$ & 51 & 86 & 59.3 & \multirow{4}{*}{ NS } \\
\hline $12-21$ & 49 & 77 & 63.6 & \\
\hline $22-31$ & 48 & 75 & 64.0 & \\
\hline$>31$ & 52 & 75 & 69.3 & \\
\hline \multicolumn{5}{|c|}{$\begin{array}{l}\text { Abbreviation: NS, not significant. } \\
\text { *The } 200 \text { complete responders included the } 102 \text { pathologically complete responders and the } 98 \text { clinically complete responders who did not undergo } \\
\text { surgical reassessment. }\end{array}$} \\
\hline
\end{tabular}




\begin{tabular}{|c|c|c|c|c|c|c|}
\hline Variable & $\begin{array}{c}\text { Parameter } \\
\text { Estimate }\end{array}$ & SE & Wald $\chi^{2}$ & $P$ & OR & $95 \% \mathrm{Cl}$ \\
\hline Intercept & -1.8987 & 0.2994 & 40.2272 & $<.0001$ & & \\
\hline Residual disease & 1.1342 & 0.2627 & 18.6367 & $<.0001$ & 3.109 & 1.858 to 5.202 \\
\hline Ascites & 0.8771 & 0.2957 & 8.7954 & .0030 & 2.404 & 1.346 to 4.292 \\
\hline
\end{tabular}

studies are assessing whether the addition of other drugs to paclitaxel and carboplatin provides a clinical benefit. ${ }^{43}$

Residual disease after initial surgery is the most important prognostic factor for advanced epithelial ovarian cancer. $^{2-6}$ For instance, according to the FIGO Annual Report No. 24, the 5-year survival rates in stage IIIc disease were $55 \%, 42.3 \%$, and $15.2 \%$, respectively, for patients with no macroscopic residuum, macroscopic residuum less than $2 \mathrm{~cm}$, and residuum more than $2 \mathrm{~cm}^{1}$ Several other clinicopathologic and biologic variables have been related to the clinical outcome of patients with this malignancy, ${ }^{2-21}$ whereas the predictive and prognostic relevance of the interval time from primary surgery to the start of chemotherapy has not yet been clarified. ${ }^{33,35}$ There are little data regarding the effectiveness of chemotherapy in relation to timing of such therapy from surgery in animal tumor models ${ }^{27-29}$ as well as in human malignancies including epithelial ovarian cancer. ${ }^{30-35}$ By assessing how a variation in the time interval between primary tumor removal and cyclophosphamide administration affected residual tumor cell kinetics and animal survival in a murine mammary adenocarcinoma, Fisher et $\mathrm{al}^{27}$ detected that the shorter the time after operation that therapy is begun, the more com- plete is the abrogation of the kinetic changes in distant tumor foci, the more effective becomes the suppression of residual tumor burden, and the more prolonged is the survival. When cyclophosphamide was given before the operation, it completely prevented the increase in labeling index resulting from tumor removal, and prolonged mice survival to the greatest extent. In a murine osteosarcoma model, the perioperative administration of cytotoxic drugs demonstrated a significant advantage in preventing systemic relapses when compared with postoperative chemotherapy. ${ }^{28}$ Conversely, in the study of Berg et $\mathrm{al}^{29}$ there was no significant difference in survival between dogs with osteosarcoma that began cisplatin and doxorubicin chemotherapy 2 days after amputation and those that started chemotherapy 10 days after surgery.

In a series including 460 stage I and II breast cancer patients who received adjuvant chemotherapy consisting of fluorouracil, doxorubicin, and cyclophosphamide, there was no difference in 4-year disease-free survival for patient subgroups with interval times from surgery to chemotherapy of less than 10 weeks, 10 to 13,14 to 17 , or $\geq 18$ weeks $\left(64 \%, 68 \%, 60 \%\right.$, and $63 \%$, respectively). ${ }^{30}$ Conversely, in the study of Pronzato et al, ${ }^{32}$ which enrolled

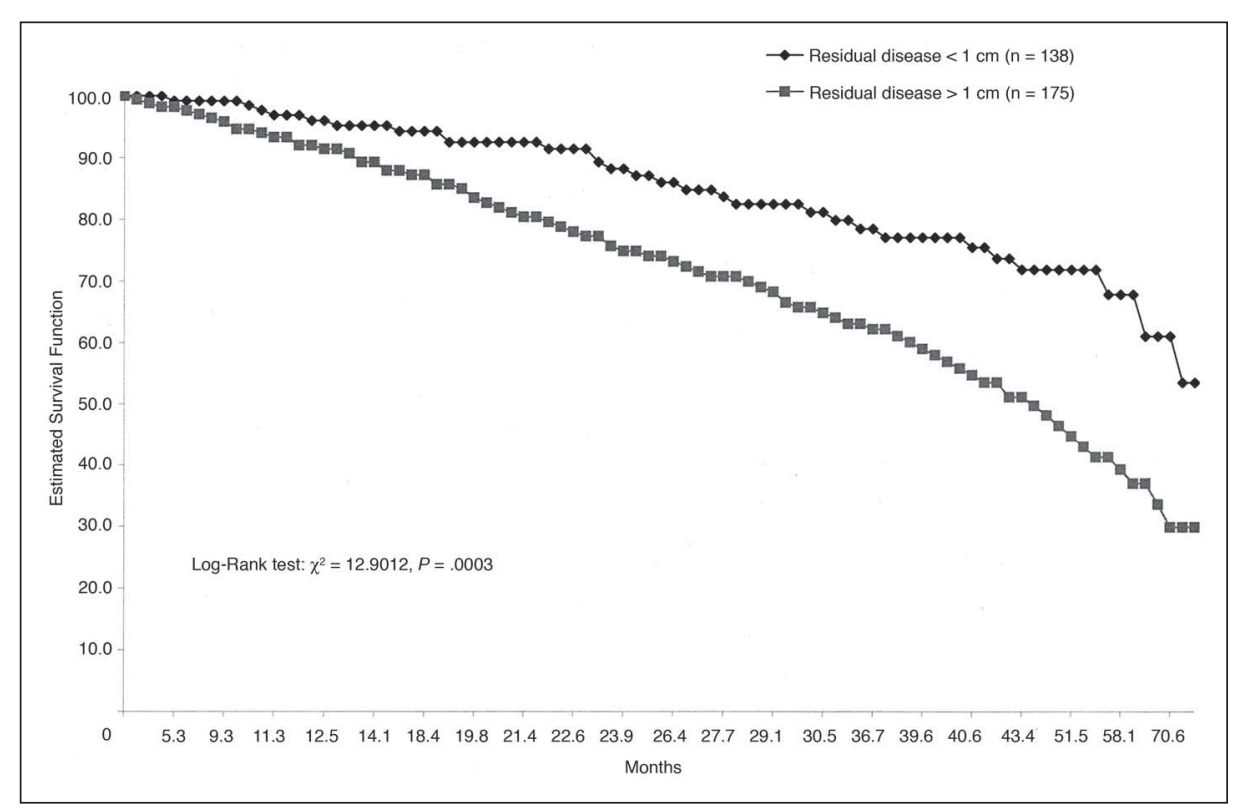

Fig 1. Overall survival in patients with advanced epithelial ovarian cancer by residual disease after primary surgery. 


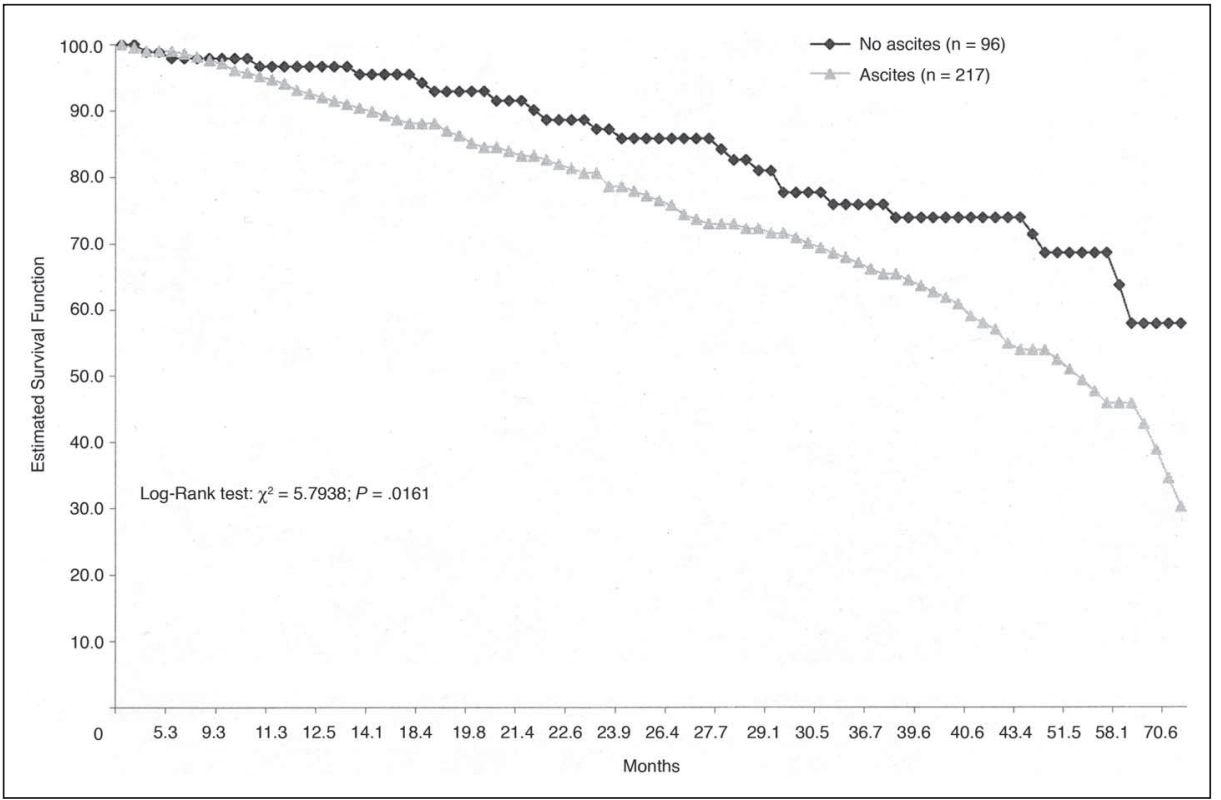

Fig 2. Overall survival in patients with advanced epithelial ovarian cancer by ascites.

229 patients with node-positive primary operable breast cancer who underwent adjuvant chemotherapy consisting of fluorouracil, methotrexate, and cyclophosphamide, survival was significantly improved in patients who began chemotherapy within 35 days from surgery compared with those who started adjuvant treatment later $(P=.01)$. Colleoni et $\mathrm{al}^{34}$ investigated the relationship between early initiation of chemotherapy, estrogen receptor (ER) status, and prognosis in 1,788 premenopausal, node-positive patients treated on different International Breast Cancer Study Group trials. Among patients with ER-negative tumors, 10 -year disease-free survival was $60 \%$ for patients who started chemotherapy within 20 days compared with $34 \%$ for those who started chemotherapy later $(P=.0003)$. Conversely, timing of chemotherapy initiation had no prognostic relevance for patients with ER-positive tumors.

For epithelial ovarian cancer, in the cohort study of Warwick et $\mathrm{al}^{33}$ including 362 patients with advanced disease treated with surgery followed by platinum-based chemotherapy, those patients with a longer interval appeared to have a worse outcome, but the interval was not an independent prognostic factor at multivariate analysis. The Scottish Gynaecological Cancer Trials Group investigated whether the length of the interval from primary surgery to

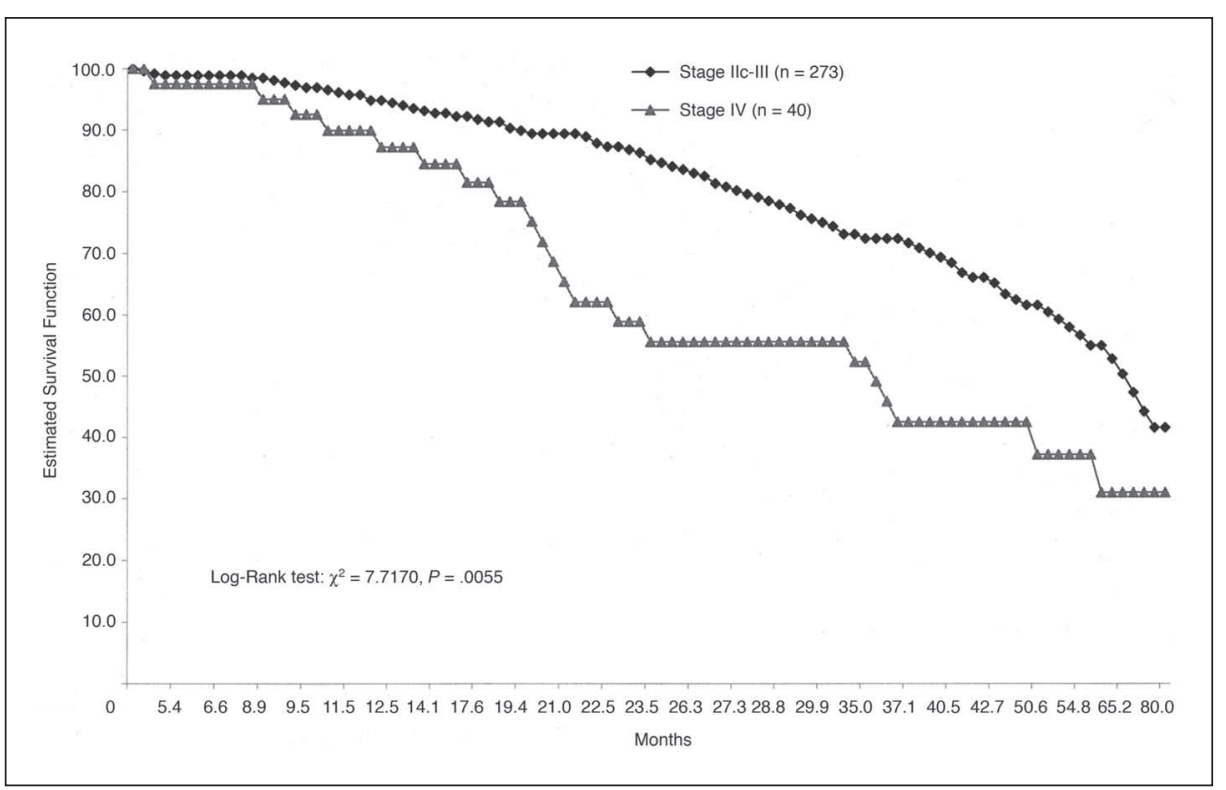

Fig 3. Overall survival in patients with advanced epithelial ovarian cancer by International Federation of Gynecology and Obstetrics stage. 


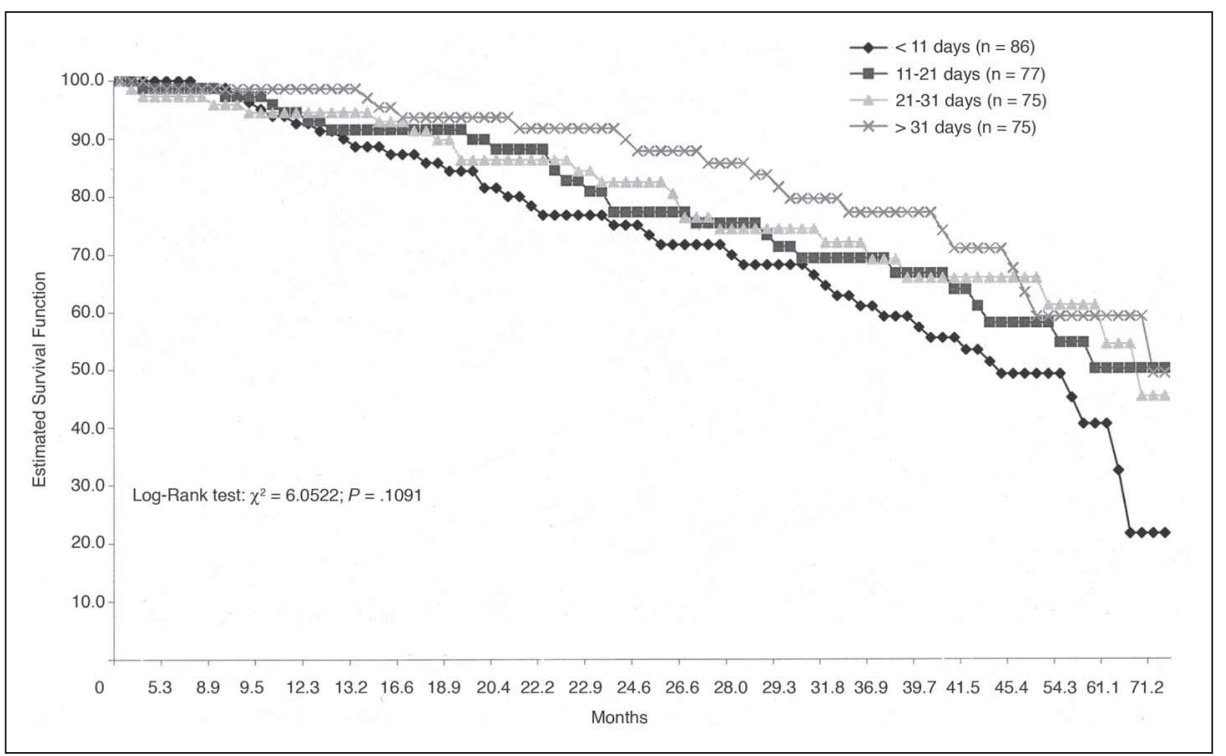

Fig 4. Overall survival in patients with advanced epithelial ovarian cancer by interval time from primary surgery to the start of taxane- plus platinum-based chemotherapy.

chemotherapy has any effect on the progression-free survival of 472 patients enrolled onto four studies who had all received platinum-containing chemotherapy in combination with either a taxane (paclitaxel or docetaxel) or with cyclophosphamide. ${ }^{35}$ The median interval from surgery to chemotherapy was 22 days (range, 5 to 113 days). Univariate analysis showed a trend for worse progression-free survival for patients with earlier therapy, but women treated earlier tended to have bulkier residual disease. Therefore, multivariate analysis revealed that the interval from surgery to chemotherapy is not an independent prognostic factor for progression-free survival.
The predictive or prognostic relevance of a variable should be assessed in a group of patients who receive homogenous treatments. In our study, we investigated the clinical relevance of time interval from primary surgery to chemotherapy in a series of 313 patients with advanced epithelial ovarian cancer who had all undergone taxaneplus platinum-based chemotherapy. The $25 \%, 50 \%$, and $75 \%$ quantiles of intervals were 11, 21, and 31 days, respectively. Residual disease after initial surgery and the absence or presence of ascites were independent predictive factors for the chance of achieving a complete response, whereas residual disease and tumor stage were

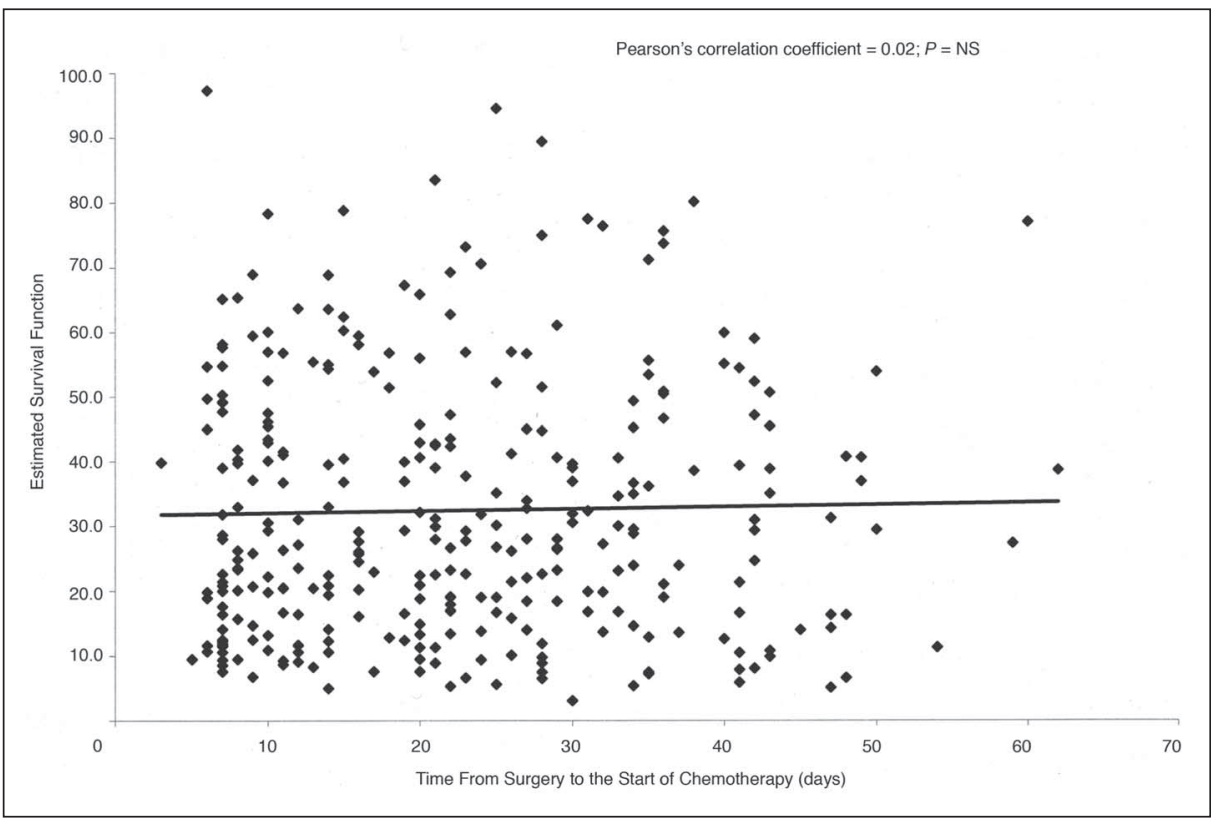

Fig 5. Relationship between interval time from primary surgery to the start of taxane- plus platinum-based chemotherapy and overall survival (nonparametric correlation analysis). 
Table 3. Variables Predictive of Overall Survival (Cox model)

\begin{tabular}{lcccrrr}
\hline \multicolumn{1}{c}{ Variable } & $\begin{array}{c}\text { Parameter } \\
\text { Estimate }\end{array}$ & SE & Wald $\chi^{2}$ & $P$ & $\mathrm{HR}$ & \multicolumn{1}{c}{ 95\% Cl } \\
\hline Stage & 0.51585 & 0.25327 & 4.1486 & .0417 & 1.675 & 1.020 to 2.752 \\
Residual disease & 0.75048 & 0.23067 & 10.5849 & .0011 & 2.118 & 1.348 to 3.329 \\
\hline
\end{tabular}

Abbreviation: HR, hazard ratio.

independent prognostic variables for overall survival. Conversely, statistical analyses failed to detect significant differences in complete response rates and survival among patients with time interval from surgery to chemotherapy shorter than 11, 12 to 21, 22 to 31 , and longer than 31 days.

From a theoretical viewpoint, residual lesions after cytoreductive surgery have a high growth fraction, and therefore the earlier the start of chemotherapy, the greater is the chance that chemotherapy controls residual disease. The currently available chemotherapy regimens obtain satisfactory response rates in patients with advanced epithelial ovarian cancer, but most responders will subsequently experience tumor recurrence and up to more than $80 \%$ of patients will need a second-line treatment for chemotherapy-resistant disease. ${ }^{47,48}$ Drug resistance is the major obstacle in developing systemic therapies for advanced cancer and might be involved particularly in the secondary treatment failure frequently seen in epithelial ovarian cancer. ${ }^{49-51}$ On the basis of somatic mutation theory, it can be hypothesized that resistant mutants arise spontaneously early in the natural history of cancers and that the likelihood of developing genetically resistant clones is closely related to cell number. ${ }^{52}$ The onset of permanent resistance accounts for the inverse relationship between cell number and curability by drugs. At the time of clinical detection, advanced epithelial ovarian cancer consists of $10^{12}$ to $10^{13}$ tumor cells and therefore often contains a high rate of genetically chemotherapy-resistant clones. This can explain why an early administration of chemotherapy after surgery seems to give no clinical benefit when compared with a more delayed treatment.

In the clinical practice, the start of chemotherapy can be delayed because of different situations, such as when patients are referred from other institutions some weeks after surgery; when patients are submitted to aggressive cytoreductive surgery with consequent recovery delay; when patients present low hemoglobin levels and need more time to recover after surgery; when patients need to be discharged home earlier after surgery to get adjusted to their cancer diagnosis before starting chemotherapy that can be administered in a outpatient facility; and in difficult cases for the pathologist, for which the morphological interpretation is not unequivocal and more time is required for additional investigations (ie, immunohistochemistry and molecular analysis) to define with certainty the histologic type of the tumor. Only a prospective, specifically planned study can definitely clarify the clinical relevance of interval time between surgery and chemotherapy. However, the currently available data failed to detect that a few weeks of delay in starting chemotherapy influences the clinical outcome of patients with advanced epithelial ovarian cancer.

\section{Authors' Disclosures of Potential Conflicts of Interest}

The authors indicated no potential conflicts of interest.

\section{REFERENCES}

1. Heintz APM, Odicino F, Maisonneuve P, et al: Carcinoma of the ovary. J Epidemiol Biostat 6:107-138, 2001

2. Hogberg T, Carstensen J, Simonsen E: Treatment results and prognostic factors in a population-based study of epithelial ovarian cancer. Gynecol Oncol 48:38-49, 1993

3. Kaern J, Tropè CG, Kristensen GB, et al: Evaluation of deoxyribonucleic acid ploidy and S-phase fraction as prognostic parameters in advanced epithelial ovarian carcinoma: A prospective study. Am J Obstet Gynecol 170:479487, 1994

4. Baker TR, Piver MS, Hempling RE: Longterm survival by cytoreductive surgery to less than $1 \mathrm{~cm}$, induction weekly cisplatin and monthly cisplatin, doxorubicin and cyclophos- phamide therapy in advanced ovarian adenocarcinoma. Cancer 74:656-663, 1994

5. Makar AP, Baekelandt M, Tropè CG, et al: The prognostic significance of residual disease, FIGO substage, tumor histology, and grade in patients with FIGO stage III ovarian cancer. Gynecol Oncol 56:175-180, 1995

6. Gadducci A, Zola P, Landoni F, et al: Serum half-life of CA 125 during early chemotherapy as an independent prognostic variable for patients with advanced epithelial ovarian cancer: Results of a multicentric Italian study. Gynecol Oncol 58:42-47, 1995

7. Goff BA, Sainz de la Cuesta R, Muntz $H G$, et al: Clear cell carcinoma of the ovary: A distinct histologic type with poor prognosis and resistance to platinum-based chemotherapy in stage III disease. Gynecol Oncol 60:412417, 1996
8. Silvestrini R, Daidone MG, Veneroni $S$, et al: The clinical predictivity of biomarkers of stage III-IV epithelial ovarian cancer in a prospective randomized treatment protocol. Cancer 82:159167, 1998

9. Nagai M, Oshita T, Fuji T, et al: Are DNA ploidy and epidermal growth factor receptor prognostic factors for untreated ovarian cancer? A prospective study. Am J Clin Oncol 24:215221, 2001

10. Buttitta F, Marchetti $A$, Gadducci $A$, et al: p53 alterations are predictive of chemoresistance and aggressiveness in ovarian carcinomas A molecular and immunohistochemical study. Br J Cancer 75:230-235, 1997

11. Tai $Y T$, Lee $S$, Niloff $E$, et al: Bax protein expression and clinical outcome in epithelia ovarian cancer. J Clin Oncol 16:2583-2590, 1998 
12. Lavarino C, Pilotti S, Oggionni M, et al: p53 gene status and response to platinum/paclitaxelbased chemotherapy in advanced ovarian carcinoma. J Clin Oncol 18:3936-3945, 2000

13. Reles $A$, Wen $W H$, Schmider $A$, et al: Correlation of p53 mutations with resistance to platinum-based chemotherapy and shortened survival in ovarian cancer. Clin Cancer Res 7:2984-2997, 2001

14. Schuyer $M$, van der Burg ME, HenzenLogmans SC, et al: Reduced expression of BAX is associated with poor prognosis in patients with epithelial ovarian cancer: A multifactorial analysis of TP53, p21, BAX and BCL-2. $\mathrm{Br} J$ Cancer 85:1359-1367, 2001

15. Gadducci A, Cosio S, Muraca $S$, et al: Molecular mechanisms of apoptosis and chemosensitivity to platinum and paclitaxel in ovarian cancer: Biological data and clinical implications. Eur J Gynaecol Oncol 23:390-396, 2002

16. Saltzman AK, Hartenbach EM, Carter JR, et al: Transforming growth factor-alpha levels in the serum and ascites of patients with advanced epithelial ovarian cancer. Gynecol Obstet Invest 47:200-204, 1999

17. Ferrandina G, Ranelletti FO, Lauriola $L$, et al: Cyclooxygenase-2 (COX-2), epidermal growth factor receptor (EGFR), and Her-2/neu expression in ovarian cancer. Gynecol Oncol 85:305310, 2002

18. Gasparini G, Bonoldi E, Viale G, et al: Prognostic and predictive value of tumour angiogenesis in ovarian carcinomas. Int $\mathrm{J}$ Cancer 69:205-211, 1996

19. Abulafia O, Triest WE, Sherer DM: Angiogenesis in primary and metastatic epithelial ovarian carcinoma. Am J Obstet Gynecol 177: 541-547, 1997

20. Terai $Y$, Ueda M, Kumagai $K$, et al: Tumor angiogenesis and thymidine phosphorylase expression in ovarian carcinomas including serous surface papillary adenocarcinoma of the peritoneum. Int J Gynecol Pathol 19:354-360, 2000

21. Bamberger ES, Perrett CW: Angiogenesis in epithelial ovarian cancer. Mol Pathol 55:348359, 2002

22. Sheldon PW, Fowler JF: The effect of irradiating a transplanted murine lymphosarcoma on the subsequent development of metastases. Br J Cancer 28:508-514, 1973

23. Milas L, Hunter N, Mason $K$, et al: Immunological resistance to pulmonary metastases in $\mathrm{C} 3 \mathrm{Hf} / \mathrm{Bu}$ mice bearing syngeneic fibrosarcoma of different sizes. Cancer Res 34:61-71, 1974

24. Simpson-Herren $L$, Sanford $A H$, Holmquist JP: Effects of surgery on the cell kinetics of residual tumor. Cancer Treat Rep 60:1749-1760, 1976
25. Schiffer LM, Braunschweiger PG, Stragand $\mathrm{JJ}$ : Tumor cell population kinetics following noncurative treatment. Antibiot Chemother 23:148-156, 1978

26. Gunduz N, Fisher B, Saffer EA: Effect of surgical removal on the growth and kinetics of residual tumor. Cancer Res 39:3861-3865, 1979

27. Fisher B, Gunduz N, Saffer EA: Influence of the interval between primary tumor removal and chemotherapy on kinetics and growth of metastases. Cancer Res 43:1488-1492, 1983

28. Bell RS, Roth YF, Gebhardt MC, et al: Timing of chemotherapy and surgery in a murine osteosarcoma model. Cancer Res 48:55335538, 1988

29. Berg J, Gebhardt MC, Rand WM: Effect of timing of postoperative chemotherapy on survival of dogs with osteosarcoma. Cancer 79: 1343-1350, 1997

30. Buzdar AU, Smith TL, Powell KC, et al: Effect of timing of initiation of adjuvant chemotherapy on disease-free survival in breast cancer. Breast Cancer Res Treat 2:163-169, 1982

31. The Ludwig Breast Cancer Study Group: Combination adjuvant chemotherapy for nodepositive breast cancer: Inadequacy of a single perioperative cycle. N Engl J Med 319:677-683, 1988

32. Pronzato $P$, Campora E, Amoroso D, et al: Impact of administration-related factors on outcome of adjuvant chemotherapy for primary breast cancer. Am J Clin Oncol 12:481-485, 1989

33. Warwick J, Kehoe S, Earl H, et al: Longterm follow-up of patients with advanced ovarian cancer treated in randomised clinical trials. $\mathrm{Br} J$ Cancer 72:1513-1517, 1995

34. Colleoni M, Bonetti M, Coates AS, et al: Early start of adjuvant chemotherapy may improve treatment outcome for premenopausal breast cancer patients with tumors not expressing estrogen receptors: The International Breast Cancer Study Group. J Clin Oncol 18:584-590, 2000

35. Flynn PM, Paul J, Cruickshank DJ: Does the interval from primary surgery to chemotherapy influence progression-free survival in ovarian cancer? Gynecol Oncol 86:354-357, 2002

36. McGuire WP, Hoskins WJ, Brady MF, et al: Cyclophosphamide and cisplatin compared with paclitaxel and cisplatin in patients with stage III and stage IV ovarian cancer. N Engl J Med 334:1-6, 1996

37. du Bois A, Luck HJ, Meier W, et al: Carboplatin/paclitaxel versus cisplatin/paclitaxel as first-line chemotherapy in advanced ovarian cancer: An interim analysis of a randomized phase III trial of the Arbeitsgemeinschaft Gynakologische Onkologie Ovarian Cancer Study Group. Semin Oncol 24:15-52, 1997 (suppl 15)
38. Conte PF, Cianci C, Gadducci A: Up date in the management of advanced ovarian carcinoma. Crit Rev Oncol Hematol 32:49-58, 1999

39. Piccart MJ, Bertelsen K, James $K$, et al: Randomized intergroup trial of cisplatin-paclitaxel versus cisplatin-cyclophosphamide in women with advanced epithelial ovarian cancer: Threeyear results. J Natl Cancer Inst 92:699-708, 2000

40. Piccart MJ, Du Bois A, Gore ME, et al: A new standard of care for treatment of ovarian cancer. Eur J Cancer 36:10-12, 2000

41. Neijt JP, Engelholm SA, Tuxen MK, et al: Exploratory phase III study of paclitaxel and cisplatin versus paclitaxel and carboplatin in advanced ovarian cancer. J Clin Oncol 18:3084 3092, 2000

42. Ozols RF: Paclitaxel (taxol)/carboplatin combination chemotherapy in the treatment of advanced ovarian cancer. Semin Oncol 27:3-7, 2000 (suppl 7)

43. Harries M, Gore M: Part I: Chemotherapy for epithelial ovarian cancer-treatment at first diagnosis. Lancet Oncol 3:529-536, 2002

44. du Bois A, Luck HJ, Meier W, et al: A randomized clinical trial of cisplatin/paclitaxel versus carboplatin/ paclitaxel as first-line treatment of ovarian cancer. J Natl Cancer Inst 95:13091329, 2003

45. Vasey PA: Survival and longer-term toxicity results of the SCOTROC study: Docetaxelcarboplatin (DC) vs. paclitaxel-carboplatin (PC) in epithelial ovarian cancer (EOC). Proc Am Soc Clin Oncol 21:202, 2002 (abstr 804)

46. Vasey PA: Role of docetaxel in the treatment of newly diagnosed advanced ovarian cancer. J Clin Oncol 21:136-144, 2003 (suppl 10)

47. McGuire WP, Ozols RF: Chemotherapy of advanced ovarian cancer. Semin Oncol 25:340348, 1998

48. Conte PF, Gadducci A, Cianci C: Secondline treatment and consolidation therapies in advanced ovarian cancer. Int J Gynecol Cancer 11:52-56, 2001 (suppl 1)

49. Sood AK, Buller RE: Drug resistance in ovarian cancer: From the laboratory to the clinic Obstet Gynecol 92:312-319, 1998

50. Goldie JH: Drug resistance in cancer: A perspective. Cancer Metastasis Rev 20:63-68, 2001

51. Schondorf T, Kurbacher CM, Gohring UJ, et al: Induction of MDR1-gene expression by antineoplastic agents in ovarian cancer cell lines. Anticancer Res 22:2199-2203, 2002

52. DeVita VT Jr: The James Ewing lecture: The relationship between tumor mass and resistance to chemotherapy-Implications for surgical adjuvant treatment of cancer. Cancer 51: 1209-1220, 1983 